\title{
Take Control of Interruptions in Your Life: Lessons from Routine Activity Theory of Criminology
}

\author{
Pankush Kalgotra \\ Oklahoma State University \\ pankush@okstate.edu
}

\author{
Andy Luse \\ Oklahoma State University \\ andyluse@okstate.edu
}

\author{
Ramesh Sharda \\ Oklahoma State University \\ ramesh.sharda@okstate.edu
}

\begin{abstract}
Steeped among the items on the dark side of information technology are personal technology interruptions. Past research has examined the negative impact of technology interruptions; however, the factors that are responsible for the increasing rate of interruptions are rarely discussed. In this study, by adapting the criminology theory of Routine Activity Theory (RAT), we propose three factors that lead to an interruption: number of interruption sources, absence of guardians, and individual targetness. Results from a survey of mobile users show that combinations of these factors have increased the interruption rate in our lives. Interestingly, just having more apps on the phones does not increase interruptions; it is a combination of the factors noted above.
\end{abstract}

\section{Introduction}

Past studies have shown that communication technologies improve productivity and efficiency of employees [1]. The ubiquity of the Internet through communication devices such as tablets, smartphones, etc. has made communication even faster and more effective. These communication technologies are useful if they are applied to enhance efficiency; however, their excessive and unnecessary use may have negative consequences with respect to productivity [2]. In this paper, our objective is to focus on one of its negative sides, interruptions.

Interruptions are considered one of the dark sides of technology, because they can have a negative impact on task performance. For example, Gupta and Sharda observed that interruptions from email arrival alerts can take an additional 5\% of a worker's day [3]. Other researchers have shown that it requires 25 minutes to resume a primary task after an interruption [4] affecting work quality [5]. Repeated interruptions also increase anxiety, exhaustion, and annoyance [6].
With the emergence of new smart mobile devices, the rate of interruptions is increasing. More than a decade ago Friedman [7] argued that technology has transformed our time to an "age of interruptions" as we continuously get interrupted by emails, instant messages, and social media alerts, with these interruptions increasing over the last ten years. Today, all communication devices have a "push" feature for notifying the user with an alert (audio/visual/tactile) when information arrives. This feature creates external interruptions that entice/force an individual to check his or her device more often. The interruptions generated by communication devices divert an individual's attention from the current task to another. Given the switching cost associated with changing tasks [8], interruptions have enormous importance in research.

The purpose of this paper is to understand the causes of perceived technology interruptions in our lives. Past research on interruptions has focused largely on the post-effects of interruptions. Here we instead look at the pre-factors in order to identify the dimensions that lead to the convergence of an interruption. To do so, we adapt Routine Activity Theory (RAT) from criminology literature [9]. Using RAT, we conclude that interruptions are increasing in human lives because more opportunities are provided to communication devices to interrupt individuals. These opportunities for interruption sources are increasing due to the lack of interruption management and higher accessibility to these sources by users.

\section{Theoretical Background}

Interruptions can be caused by 1) an external stimulus (such as an email alert) or 2) an internal stimulus (such as recalling unfinished work); however, our focus in this study is only on external interruptions through computer-mediated communication technologies such an email alerts, text message alerts, etc. An external interruption is defined as an external 
event that pauses the current task and demands mental resources [10]. These are the stimuli or triggers leading to attention-shift from one task to another. Due to an interruption convergence, the conscious mind gets occupied by the new task and the primary task becomes the background task [11]. We note that merely a "ding" sound on the smartphone is not considered an interruption, but instead an interruption takes place when an actual response to the external stimulus is made. However, an external stimulus is still a part or prerequisite for an interruption to be converged. It should be noted that an interruption is different from a distraction. A distraction is detected by different sensory channels while interruptions are detected by the same sensory channels as the primary task [12].

Several possible dimensions of the impact of interruptions on performance have been discussed by researchers in the past. McFarlane [13] identified eight dimensions underlying human interruptions: source, individual characteristics of receiver, coordination method, meaning of interruption, method of expression, channel of conveyance, change by interruption, and the effect of an interruption. Later, Speier et al. [14] provided an interruption framework where they focused on characteristics of interruptions, primary tasks, and decision makers to explain the impact of interruptions on performance. Basoglu et al. [15] extended the Speier et al. framework and concluded that interruptions have indirect effects on performance through cognitive load. This previous research provides tremendous insights into interruption behavior; however, these frameworks aimed to study the post-effects of an interruption. Little work has been done to identify the factors responsible for the increasing interruption rate in humans' lives (i.e. pre-effects).

Modern smart hand-held devices have increased the interruption rate as an immediate response to a technology interruption directs the user's conscious mind towards external rewards. As discussed in media richness theory [16] and media synchronicity theory [17], the process is immediate because individuals attempt to reduce the level of uncertainty and synchronicity in the communication. The nature of fast communication through new technologies can be explained by media synchronicity theory's process of convergence [17]. Process of convergence involves the transmission of well-known information and may require fewer cognitive resources to process it. High synchronicity between the communicators may be appropriate as less time is required to process such information. The technology interruptions follow the process of convergence as communicators know each other well and thus, less time is required to process the information.

The convergence of an interruption is enabled by facilitating conditions. Facilitating conditions are the objective factors in the environment that make an act easy to do [18]. These factors reduce or eliminate the potential barriers to perform an action [19]. In the context of technology interruptions, facilitating conditions remove barriers for the technology to interrupt users, thereby generating more opportunities for the technology to interrupt. Facilitating conditions can be due to the technology, environment, or individual [20]. We recognize all kinds of psychological, behavioral, and environmental reasons for the interruption rate $[14,21]$, but our aim is to find technological and individual facilitating conditions responsible for the increasing interruption rate in our lives.

Technology interruptions are increasing due to emerging computer-mediated communication technologies. Hence, the technology and communication devices have a role to play in this behavior. In addition to the role of technology in increasing the interruption rate, the user also has a partial role to play because he has control over the technology and interruptions. A target of an interruption plays a role to convert an external stimulus into an interruption. A user or target is partially responsible for providing more opportunities to the sources of interruptions. To find the facilitating factors that provide more opportunities to the communication technology to generate interruptions, we adapt a criminology approach known as routine activity approach.

\section{Routine Activity and Interruptions}

Routine Activity Theory (RAT) can help us to identify the necessary facilitating conditions for an interruption to converge. In criminology, RAT states that for a crime event to occur, three conditions are required: 1) an availability of a source, 2) a suitable target, and 3) the absence of a capable guardian. The same logic is applied in our context that there is a need of a source, a target, and an absence of a guardian for the convergence of an interruption. We first introduce RAT and then adapt it for our phenomenon. 


\subsection{Routine Activity Theory}

Routine activity theory was proposed by Cohen $\&$ Felson [9] in criminology and is concerned with the factors that affected the crime rate in United States from 1947-1974. Despite improvement in all aspects traditionally thought responsible for crime such as the unemployment rate, median household income, dropout rate, etc., the urban crime rate significantly increased during that period. Rather than focusing on the characteristics of the criminals, the authors stated that changes in human lifestyles resulted in an increase in the crime rate. It was hypothesized that after World War II, the routine activities of human beings changed, which provided more opportunities for crime. According to RAT, a crime event is distributed in space and time with three requirements: a motivated offender, a suitable target, and the absence of capable guardians to prevent crime. A source of a crime, or motivated offender, is a minimal condition for a crime and thus the number of possible offenders in an area affect the crime rate. With respect to the requirement of the absence of guardianship, number of crimes can increase if there is no one to guard the victim, such as the police. Thus the guardianship refers to deterrents of crime such as neighborhood watches, alarm systems, etc. Finally, crime rate is impacted by the targets' suitability, which is defined as a function of physical visibility and access. For example, people going on extended vacations leaving their houses are suitable targets for burglaries or theft. The premise of the argument in RAT was that the target, or victim, has a role to play in a crime event. Due to lifestyle and routine activities, an individual can make him or herself a greater target for a possible crime.

Since 1979, RAT has been highly used to study the factors leading to different types of crime including internet crime. Groff applied RAT to study street robbery and found that the time spent away from home increases the crime rate [22]. On the other hand, Pratt et al. [23] studied Internet fraud and concluded that spending more time on the Internet increases opportunities for Internet fraud. Our purpose in this paper is to not get into a discussion about the political implications of the argument of RAT that crime rates are affected by all three factors, but to use this theory to understand the factors that lead to increased technology interruptions.

\subsection{RAT and Interruptions}

Applying RAT to understand interruptions, we propose that for an external interruption to occur, three conditions are necessary: a source, a suitable target (or targetness, as defined later), and an absence of a capable guardian(s). Similar to RAT's interpretation of crime, we define an interruption as an event that converges in space and time in the presence of the above mentioned three requirements. We describe each criterion below separately and how each criterion is related to frequency of interruptions by communication devices such as smartphones, tablets, smart-watches, etc. Our aim is to find factors to help explain Interruption Frequency (IF), defined as the frequency at which the sources of interruptions successfully take focus away from the primary task.

Number of Sources (NOS): A source is defined as a device or an application that seeks attention and triggers an interruption. It is a property of the communication device causing a stimulus. The use and number of communication applications, such as messenger, email, social media, etc., have increased over time [24]. All of these are potential sources of external interruptions. A 'push' feature in the devices is used by the 'apps' that constantly generates alerts and interrupts the user. In fact, the availability of a source is a necessary condition for an external interruption much like a criminal is needed to commit an offense. Having more sources is likely to increase the interruption rate. Just as the higher presence of motivated offenders can lead to more crime events, the sources of interruptions are also motivated to get attention from a user and their higher presence is hypothesized to cause more interruptions.

\section{H1: An increase in the number of interruption sources will increase the frequency of interruptions.}

Absence of guardians (AOG): This phenomenon is adapted from "absence of guardianship" in RAT and modified in the context of technology interruptions. With respect to the communication technology, $a$ guardian is defined as a tool, application, or any medium that reduces an opportunity for the source to interrupt the target. In the case of smart technology interruptions, use of any software or notification settings of an app to manage interruptions by turning off alerts and notifications or keeping the phone silent can act as a guardian. A guardian acts as a wall between a source and a target, and thereby reduces the likelihood of the convergence of an interruption. An absence of a guardian is likely to provide more opportunities to the communication technologies to interrupt the user. 
H2: The greater the degree of absence of guardians the greater the frequency of interruptions.

Targetness: In addition to the source of an interruption, another requirement for the convergence of an external interruption is the availability of a target, much like in the crime setting. It is obvious that the target of an interruption is the user himself and for an interruption source, there will always be one target. However, in our context, it is more useful to understand to what extent a user makes themselves a target of interruptions. The term we use for this phenomenon is Targetness. We describe targetness in terms of proximity of the user to interruption sources. It is defined as the degree to which an individual positions oneself in an environment suitable for the proximal sources to interrupt him. In other words, it is the extent to which an individual makes oneself an object of interruptions, by making oneself a target of an interruption. It is under the control of the user to create circumstances for easy interruptions leading to interruption convergence. However, the sources that interrupt the users are the criminals.

Modern human lifestyle has made us dependent on technology for almost everything, which makes users the potential targets of interruptions. For example, carrying communication devices during an important meeting makes a user a more suitable target of interruptions. If an employee does not hold a smartphone in his or her hand during a meeting, there will be less possibility to get interrupted. Users provide more opportunities to the technology to interrupt them by increasing their targetness. The main argument is that some part of the interruption rate in humans' lives is initiated by the human himself. It is not just the devices that are creating interruptions, it is also the user who is making himself a target of an interruption. Hence, we hypothesize that the interruption rate increases with increasing targetness.

\section{H3: An increase in targetness will increase the frequency of interruptions.}

Variable definitions and the hypothesized model are presented in Table 1 and Figure 1 respectively.

\section{Methods}

The focus of this research is to measure the Interruption Frequency from one specific device, a smartphone. Thus, all measures used in this study are related to smartphones. The participants in the study were students at a large Midwestern university having
Table 1. Variable definitions

\begin{tabular}{|c|l|}
\hline $\begin{array}{c}\text { Construct } \\
\text { sources }\end{array}$ & $\begin{array}{l}\text { The number of devices or device } \\
\text { applications that seek attention and } \\
\text { trigger interruptions. }\end{array}$ \\
\hline Targetness & $\begin{array}{l}\text { Degree to which an individual positions } \\
\text { himself in an environment suitable for } \\
\text { proximal sources to interrupt him. }\end{array}$ \\
\hline $\begin{array}{c}\text { Number of } \\
\text { guardians }\end{array}$ & $\begin{array}{l}\text { The number of tools, applications, or } \\
\text { any medium that reduces the } \\
\text { opportunity for the source to interrupt } \\
\text { the target. }\end{array}$ \\
\hline $\begin{array}{c}\text { Interruption } \\
\text { Frequency }\end{array}$ & $\begin{array}{l}\text { Frequency at which the source of } \\
\text { interruptions successfully takes the } \\
\text { focus of the target away from the } \\
\text { primary task. }\end{array}$ \\
\hline
\end{tabular}

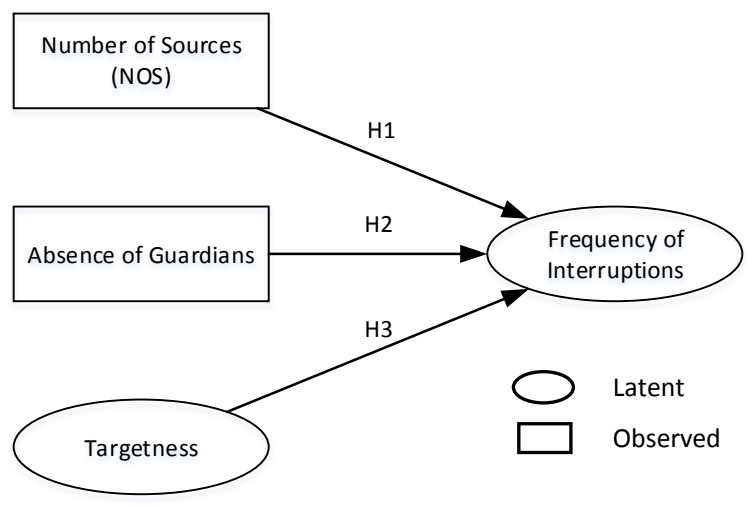

Figure 1. Research Model

sufficient experience using smartphones. The study was conducted in two phases. In the first phase, a pilot test was conducted to test new measures developed. A survey was sent to 85 undergraduate students at a large university in the Midwest US, for analyzing the scales developed. The analysis from the first phase resulted in refinement of the items. The refined measures were used in the second phase to test the hypothesized model. The final survey was sent to 155 students, out of which 134 responded. Ten outliers were removed and five responses were not considered due to the incomplete reports. Therefore, our sample size was 119. Half of the participants were females. More than 95\% of them were Caucasians and between 18-25 years of age.

To assess non-response bias, we compared the values using t-tests on each of the four variables in the model between the first and last quartiles. Previous research suggests that late responders represent a more "typical" respondent, so if there is no difference in responses between early and late responders, non- 
response bias is not present [25]. Results showed no significance in all four t-tests $(\mathrm{p}>0.05)$, indicating no non-response bias.

\subsection{Measures}

For data collection, we used self-reports. All constructs were created by the authors and refined before collecting the data for the main analysis. For measuring the construct "Number of Sources" (NOS), we provided a list of 13 most popular apps to the participants, according to Nielson reports (the list is frequently updated) [26]. The respondents indicated the apps they use and the type of notifications for each app. We also gave the opportunity to write-in other apps they use. Hence, the construct NOS was measured as the sum of communication applications they reported using.

The notifications for iOS users and Android users were different. For iOS devices, the notification types are banners, badges, alerts, sound, and vibration. For android devices, the types of notifications are system bar, LED lights, toast message, badges, sound, and vibration. The construct "Absence of Guardians" (AOG) was measured from the information about notifications used by the users. This was calculated as a composite variable explaining the average number of notifications used by a user per application.

The third construct "Targetness" was measured using a multi-item scale. During the pilot study, five indicators to measure the targetness were developed. After refinement, three items were finally used as listed in Appendix A. These were: "I keep my smartphone with me at all times", "I keep my smartphone with me wherever I go" and "My smartphone is always accessible." All items were measured on a five-point Likert scale (Strongly Disagree/Strongly Agree). As per the definition of Targetness, its indicators include an element of proximity.

Similar to Targetness, the construct for the dependent variable "Interruption Frequency" (IF) was measured with a multi-item scale refined during the pilot study (See Appendix A for a complete list of items). After refinement, a three-item scale measuring IF was used including "Notifications from my smartphone repeatedly take my focus away from my current task", "Notifications from my smartphone often disrupt my concentration" and "Notifications from my smartphone regularly switch my attention from my primary task." All items were measured on a five-point Likert scale (Strongly Disagree/Strongly Agree).

\section{Analysis}

\subsection{Measurement Model}

Covariance-based confirmatory factor analysis was used to assess the measurement model. Overall, the factor model fit the data extremely well with several model fit indices used to assess the quality of the CFA, including the chi-square statistic $\left(\chi^{2}=\right.$ 6.99[8], $\mathrm{p}=0.53)$, the CFI (1.00), the SRMR (0.03), and the RMSEA $(0.00,[\mathrm{CI}=0.00,0.09])$.

Validity and reliability were assessed using several metrics (see Table 2). First, the standardized loadings of each observed item was greater than 0.7 indicating that the items are valid [27] and the constructs are explaining more than $50 \%$ of the variance in each item. To test construct reliability of the scales developed, Cronbach's alpha and composite reliability were computed. Both constructs had values of Cronbach's alpha and composite reliability greater than 0.7, indicating that the scales developed for Targetness and Interruption Frequency were internally consistent and reliable [28]. Convergent validity was assessed using the average variance extracted (AVE), with all values greater than the recommended cutoff of 0.5 [28]. Discriminant validity of the scales was tested by comparing the correlation between the two latent constructs to the square root of the AVE for each construct. The square root of the AVEs of every construct was found to be greater than their correlation, indicating good discriminant validity. The correlation matrix of all variables and factor loadings are listed in Appendix B and C respectively.

Table 2. Cronbach's alpha, composite reliability, average variance extracted, and correlations for the measurement model, with square root of the AVE along the diagonal.

\begin{tabular}{|l|r|r|r|r|r|}
\hline \multicolumn{4}{|c|}{} & \multicolumn{1}{c|}{} & \multicolumn{2}{c|}{ Correlations } \\
\cline { 2 - 7 } & \multicolumn{1}{|c|}{ Alpha } & \multicolumn{1}{c|}{ CR } & \multicolumn{1}{c|}{ AVE } & \multicolumn{1}{c|}{ IF } & \multicolumn{1}{c|}{ T } \\
\hline Interruption Frequency (IF) & 0.81 & 0.80 & 0.58 & 0.76 & \\
\hline Targetness (T) & 0.90 & 0.90 & 0.90 & 0.13 & 0.95 \\
\hline
\end{tabular}

Before testing the hypothesized model, common method variance was assessed to verify that the effects in the model are not due to the method only. To test for common method variance in the model, we used Harman's single factor CFA approach where all items are forced to load on a single factor [29]. If one factor explains most of the variance, there is a concern of 
CMB. Moreover, the proposed CFA model is compared with the single factor model and chi-square difference test is conducted. If the chi-square difference test is significant, it indicates less of a problem with CMV [30]. Specifically, we used the Satorra-Bentler scaled chi-square difference test to compare the two models. The chi-square difference was statistically significant $\left(\Delta \chi^{2}[1]=46.7, \mathrm{p}<0.001\right)$, based on which we conclude that the proposed model is significantly different than the single factor model. Hence, there is no major concern for common method variance in our study.

\subsection{Structural Model}

To test the hypothesized model, covariance-based structural equation modeling was used (CB-SEM). There were three exogenous variables and one endogenous variable as shown in Figure 2. The exogenous variables were Targetness, Number of Sources (NOS), and Absence of Guardians (AOG), with the endogenous variable of Interruption Frequency (IF). We also controlled for gender as interruptions are handled differently by males and females [31]. The model fits very well with all the model fit indices satisfying the required criteria $\left(\chi^{2}=20.4[23], \quad \mathrm{p}=0.61, \quad \mathrm{CFI}=1.00, \quad \mathrm{SRMR}=0.07\right.$, $\mathrm{RMSEA}=0.00 \quad[\mathrm{CI}=0.00,0.06])$. The standardized direct effects of targetness $(0.28, \mathrm{p}=0.003)$ and AOG (0.27, $\mathrm{p}=0.01)$ on Interruption Frequency were positive and statistically significant. However, the effect of NOS on Interruption Frequency was not statistically significant $(0.06, \mathrm{p}=0.57)$. The variance explained in the endogenous variable of Interruption Frequency was $32 \%$ (see Figure 2).

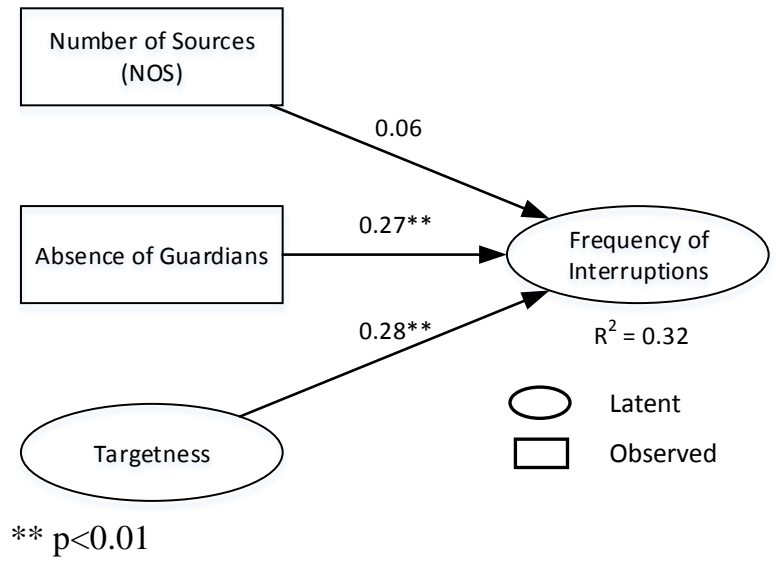

Figure 2. Structural Model

\section{Results and Discussion}

Adapting Routine Activity Theory (RAT), our aim in this study was to better understand the causes of interruptions. Hypothesis 1 involved the impact of number of sources on Interruption Frequency. It was not supported $(b=0.06, p=0.57)$. This indicates that we did not find the number of sources to have a significant impact on Interruption Frequency. It implies that using a greater number of interruption sources such as smartphone applications does not necessarily mean that more interruptions will occur. A possible explanation is that a user may have certain specific smartphone apps that generate more interruptions regardless of the total number of applications he uses. It could also mean that the notification mechanisms are different for different apps.

Hypothesis 2 examined the impact of the absence of guardians on the Interruption Frequency. This hypothesis is strongly supported $(b=0.27, p=0.01)$. It is evident that if more opportunity is provided to the sources with no barrier, Interruption Frequency is likely to increase. If users do not customize their interruptions and do not make an attempt to create obstructions between sources and themselves, the sources will ultimately trigger the alerts resulting in interruptions.

Finally, the third hypothesis examined the relationship of user targetness with Interruption Frequency. This hypothesis is supported $(b=0.28$, $\mathrm{p}=0.003$ ). This implies the frequency of interruptions is likely to increase if a user provides opportunities to interruption sources by exposing oneself to these sources. It is the individual behavior in addition to the properties of the technology that indicates the users themselves are partially responsible for the number of interruptions in their lives. This is analogous to the argument derived from RAT that the lifestyles of the crime targets may have played a role in the increase in crime.

In our model, two out of three hypotheses were supported. A post-hoc power analysis was run to verify that we had the necessary sample size to find the necessary effect size. First, an overall SEM effect size analysis showed that in order to find a medium effect size, a minimum sample of 90 subjects would be needed [32]. Next, a partial $\mathrm{R}^{2}$ analysis showed that, in order to find at least a 0.1 increase in $\mathrm{R}^{2}$ when moving from two predictors to three, a minimum of 117 subjects would be needed. Both these analyses 
suggest sufficient sample size in our study to find moderate effects [33].

To better understand the relationship of the number of sources on Interruption Frequency, we provide an alternate explanation by re-specifying the model (see Figure 3). In the alternate model, an indirect effect of number of sources on Interruption Frequency through the absence of guardians (AOG) is considered. The reasoning is that if there is a greater number of sources, there will be more opportunities for an absence of guardians with regard to all the sources. This is due to the increased information load from multiple sources that causes the managing of guardians for multiple sources to become difficult [34]. As the number of apps increases on one's phone, it is possible that notification settings are not adjusted. Hence, the higher the NOS, the higher the AOG, which ultimately affects the Interruption Frequency. The standardized coefficient of the relationship from NOS to AOG is statistically significant $(b=0.55, p<0.001)$.

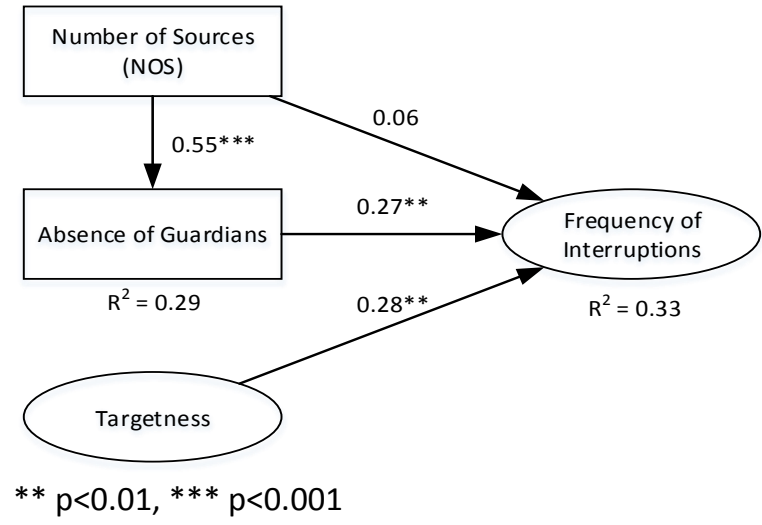

Figure 3. Alternate Model

We also analyzed the indirect effect of NOS on IF through AOG, which was also statistically significant $(b=0.15, p=0.01)$. In the post-hoc analysis, we also tested the model by removing AOG from the original model, and we found NOS to be significantly related to IF. Therefore, we conclude that AOG fully mediates the effect of NOS on IF [35].

Being an exploratory study in this area, there are a few issues we recognize. First, the constructs named "Number of Sources" and "Absence of Guardian" were computed as composite variables. One cannot assess the reliability and validity of a composite variable [36]. Second, the construct "Interruption Frequency" is not measured with high objectivity. In our future work, we will explore other methods (diaries, logs, etc.) to record the actual frequency of interruption. Third, age of a user may also impact the Interruption Frequency. Our data included undergraduate students from one class, thus there was little variance in the age. Fourth, the data were collected through surveys, not through actual analysis of apps on the users' phones, thus, limiting internal validity [37]. Finally, the subjects in our research have constant access to campus-based $\mathrm{Wi}-\mathrm{Fi}$, but future research could look at restrictions to app use due to availability of Internet connections.

Nevertheless, our study has some interesting theoretical and practical implications. The aim of our study was to explore a new theory adapting the concept of routine activities from the criminology literature. Previous research has primarily studied the impact of interruptions on outcome variables. This study adds to our understanding about the causes of interruptions. We explore the reasons why Interruption Frequency increases due to smart technologies. Our main finding is that the joint properties of the technology and the individual play significant roles for increasing interruptions. We also contribute in the development of new constructs such as Targetness and Interruption Frequency.

Our results also have several practical implications. Our research suggests users should customize notifications as well as adopt other "guardian measures" so that sources of interruptions do not have the opportunity to interrupt. We view the problem of interruptions from two sides: technologyinitiated and user-initiated. Hence, technology and behavior are both required to be controlled by the users.

\section{Concluding Remarks and Future Research}

This study adapted routine activity theory and provided a new lens to view the problem of technology interruptions. There has been much discussion in popular media as well as scholarly journals about the impact of interruptions. Before we can truly manage the problem, it is critical to understand the reasons for the convergence of interruptions in addition to the impact of the interruptions. This exploratory study is a pilot attempt at adapting a theory that has been used to understand a related phenomenon. Future work will involve developing an application to help understand Interruption Frequency and the underlying factors more objectively. There is also room to study the 
impact of interruptions. A related issue is the habit of phone users to check their devices for any new updates. This habit is potentially related to the increasing targetness of the users to get interrupted. Our research provides the necessary starting point for future research to build on by providing a first step in better understanding the causal sources of technology interruptions in our daily lives.

\section{References}

1. Pitichat, T., Smartphones in the workplace: Changing organizational behavior, transforming the future. LUX: A Journal of Transdisciplinary Writing and Research from Claremont Graduate University, 2013. 3(1): p. 13.

2. Soror, A.A., et al., Good habits gone bad: Explaining negative consequences associated with the use of mobile phones from a dual-systems perspective. Information Systems Journal, 2015.

3. Gupta, A. and R. Sharda, SIMONE: A Simulator for Interruptions and Message Overload in Network Environments. International Journal of Simulation and Process Modelling, 2008. 4(3-4): p. 237-247.

4. González, V.M. and G. Mark, Managing Currents of Work: Multi-tasking Among Multiple Collaborations. 2005, Springer Netherlands: Dordrecht. p. 143-162.

5. Altmann, E.M., J.G. Trafton, and D.Z. Hambrick, Momentary interruptions can derail the train of thought. Journal of experimental psychology.General, 2014. 143(1): p. 215-226.

6. Lin, B.C., J.M. Kain, and C. Fritz, Don't interrupt me! An examination of the relationship between intrusions at work and employee strain. International Journal of Stress Management, 2013. 20(2): p. 77.

7. Friedman, T., The age of interruption. New York Times, 2006. 5.

8. Rogers, R.D. and S. Monsell, Costs of a predictible switch between simple cognitive tasks. Journal of experimental psychology: General, 1995. 124(2): p. 207.

9. Cohen, L.E. and M. Felson, Social change and crime rate trends: A routine activity approach. American sociological review, 1979: p. 588-608.

10. O'Conaill, B. and D. Frohlich. Timespace in the workplace: Dealing with interruptions. in Conference companion on Human factors in computing systems. 1995. ACM.

11. Miyata, Y. and D.A. Norman, Psychological issues in support of multiple activities. User centered system design: New perspectives on human-computer interaction, 1986: p. 265-284.

12. Cohen, S., Aftereffects of stress on human performance and social behavior: a review of research and theory. Psychological bulletin, 1980. 88(1): p. 82.

13. McFarlane, D.C., Interruption of people in human-computer interaction: A general unifying definition of human interruption and taxonomy. 1997, DTIC Document.

14. Speier, C., I. Vessey, and J.S. Valacich, The Effects of Interruptions, Task Complexity, and Information Presentation on ComputerSupported Decision-Making Performance. Decision Sciences, 2003. 34(4): p. 771-797.

15. Basoglu, K.A., M.A. Fuller, and J.T. Sweeney, Investigating the effects of computer mediated interruptions: an analysis of task characteristics and interruption frequency on financial performance. International journal of accounting information systems, 2009. 10(4): p. 177-189.

16. Daft, R.L. and R.H. Lengel, Organizational information requirements, media richness and structural design. Management science, 1986. 32(5): p. 554-571.

17. Dennis, A.R., R.M. Fuller, and J.S. Valacich, Media, tasks, and communication processes: $A$ theory of media synchronicity. MIS quarterly, 2008. 32(3): p. 575-600.

18. Triandis, H.C. Values, attitudes, and interpersonal behavior. in Nebraska symposium on motivation. 1979. University of Nebraska Press.

19. Thompson, R.L., C.A. Higgins, and J.M. Howell, Personal computing: Toward a conceptual model of utilization. MIS quarterly, 1991: p. 125-143.

20. Engeström, Y., R. Miettinen, and R.-L. Punamäki, Perspectives on activity theory. 1999: Cambridge University Press.

21. Dismukes, R. and J. Nowinski, Prospective memory, concurrent task management, and pilot error. Attention: From theory to practice, 2006: p. 225-236.

22. Groff, E.R., Simulation for theory testing and experimentation: An example using routine activity theory and street robbery. Journal of Quantitative Criminology, 2007. 23(2): p. 75-103.

23. Pratt, T.C., K. Holtfreter, and M.D. Reisig, Routine Online Activity and Internet Fraud Targeting: Extending the Generality of Routine Activity Theory. Journal of Research in Crime and Delinquency, 2010. 47(3): p. 267-296. 
24. Fox, S. and L. Rainie, The Web at 25 in the US. Pew Research Center's Internet \& American Life Project, 2014. 27.

25. Armstrong, J.S. and T.S. Overton, Estimating nonresponse bias in mail surveys. Journal of marketing research, 1977: p. 396-402.

26. Nielsen. [cited 2016 April 2016]; Available from: http://www.nielsen.com/my/en/top10s.html.

27. MacKenzie, S.B., P.M. Podsakoff, and N.P. Podsakoff, Construct measurement and validation procedures in MIS and behavioral research: Integrating new and existing techniques. MIS quarterly, 2011. 35(2): p. 293334.

28. Fornell, C. and D.F. Larcker, Evaluating structural equation models with unobservable variables and measurement error. Journal of marketing research, 1981: p. 39-50.

29. Podsakoff, P.M., et al., Common method biases in behavioral research: a critical review of the literature and recommended remedies. Journal of applied psychology, 2003. 88(5): p. 879.

30. Kline, R.B., Principles and practice of structural equation modeling. 2015: Guilford publications.

31. Kalgotra, P., Sharda, R. and McHaney, R. Understanding the Impact of Interruptions on Knowledge Work: An Exploratory Neuroimaging Study. in 49th Hawaii International Conference on System Sciences (HICSS). 2016. Koloa, HI.

32. Westland, J.C., Lower bounds on sample size in structural equation modeling. Electronic Commerce Research and Applications, 2010. 9(6): p. 476-487.

33. Faul, F., et al., Statistical power analyses using $G^{*}$ Power 3.1: Tests for correlation and regression analyses. Behavior research methods, 2009. 41(4): p. 1149-1160.

34. Speier, C., J.S. Valacich, and I. Vessey, The influence of task interruption on individual decision making: An information overload perspective. Decision Sciences, 1999. 30(2): p. 337-360.

35. Baron, R.M. and D.A. Kenny, The moderatormediator variable distinction in social psychological research: Conceptual, strategic, and statistical considerations. Journal of personality and social psychology, 1986. 51(6): p. 1173.

36. Bollen, K.A., Evaluating effect, composite, and causal indicators in structural equation models. Mis Quarterly, 2011. 35(2): p. 359-372.

37. Trochim, W., J. Donnelly, and K. Arora, Research methods: The essential knowledge base. 2015: Nelson Education.

\section{Appendix A: Multi-item scales}

Targetness

- I keep my smartphone with me at all times.

- I keep my smartphone with me wherever I go.

- My smartphone is always accessible.

Interruption Frequency

- Notifications from my smartphone repeatedly take my focus away from my current task.

- Notifications from my smartphone often disrupt my concentration.

- Notifications from my smartphone regularly switch my attention from my primary task.

Number of sources (Smartphone Apps)

- Text messages, Facebook, YouTube, Twitter, Skype, Facebook Messenger, WhatsApp, Instagram, Google Plus, Snapchat, Music, Email, News and others can be added manually.

Different types of Notifications

- $\quad$ iOS - Banner, Badges, Alerts, Sound and Vibration.

- Android - System bar, LED Light, Toast Message, Badges, Sound and Vibration. 
Appendix B: Correlation Matrix

Correlation Matrix

\begin{tabular}{|l|l|l|l|l|l|l|l|l|l|}
\hline & Target1 & Target2 & Target3 & IF1 & IF2 & IF3 & Guardians & Source & Gender \\
\hline Target1 & 1 & & & & & & & & \\
\hline Target2 & 0.844 & 1 & & & & & & & \\
\hline Target3 & 0.7 & 0.734 & 1 & & & & & & \\
\hline IF1 & 0.301 & 0.285 & 0.335 & 1 & & & & & \\
\hline IF2 & 0.288 & 0.255 & 0.223 & 0.597 & 1 & & & & \\
\hline IF3 & 0.214 & 0.167 & 0.186 & 0.588 & 0.584 & 1 & & & \\
\hline Guardians & 0.19 & 0.145 & 0.195 & 0.29 & 0.22 & 0.224 & 1 & & \\
\hline Source & 0.207 & 0.216 & 0.231 & 0.199 & 0.229 & 0.198 & 0.546 & 1 & \\
\hline Gender & 0.067 & 0.078 & -0.001 & 0.29 & 0.325 & 0.296 & -0.049 & 0.025 & 1 \\
\hline
\end{tabular}

Appendix C: Factor loadings of Multi-Item Scales

Indicators Loadings on Factors

\begin{tabular}{|l|l|l|}
\hline Indicators & Targetness & IF \\
\hline Target1 & 0.903 & 0.329 \\
\hline Target2 & 0.934 & 0.34 \\
\hline Target3 & 0.784 & 0.285 \\
\hline IF1 & 0.287 & 0.788 \\
\hline IF2 & 0.28 & 0.771 \\
\hline IF3 & 0.271 & 0.743 \\
\hline
\end{tabular}

